\title{
BLOOD PRESSURE AND OLD AGE
}

BY

TREVOR H. HOWELL

From the Royal Hospital, Chelsea

Received June 20, 1942

Twenty years ago, Thompson and Todd (1922) published an article entitled " Old age and blood pressure problems." They recorded the blood pressure in a hundred and two Chelsea pensioners over the age of seventy-five, noting that forty-six of them had systolic figures over $150 \mathrm{~mm}$. and twenty-three over $170 \mathrm{~mm}$. They also found that apparently similar men in normal health showed great differences in blood pressure without obvious cause.

Several other writers have published figures of blood pressure readings in old age and these show considerable variation in their estimate of the normal. For example, Thewlis (1941) quotes Saller as stating that the average figures for men and women between the ages of sixty and sixty-seven are 173/93 and 216/102 respectively, and between sixty-seven and eighty-nine 186/80 and 222/112 respectively. Willius (1931), on the other hand, taking seven hundred cases over the age of seventy-five, attending the Mayo clinic, has figures varying from $109 / 75$ to $127 / 74 \mathrm{~mm}$. as the averages of his (two-year) groups. Even so, 74 per cent of his patients had systolic figures over $140 \mathrm{~mm}$. and 40 per cent diastolic figures over $90 \mathrm{~mm}$. Robinson and Brucer (1939), who took normal cases for insurance purposes, Bowes (1917), Richter (1925), and Wildt (1912) all published figures for five-year age groups. These are shown in Table I below, together with those of the present series.

TABLE I

Age and Mean Blood Pressure

\begin{tabular}{|c|c|c|c|c|c|}
\hline Age Groups & Robinson \& Brucer & Richter & Wildt & Bowes & Howell \\
\hline $\begin{array}{c}60-64 \\
65-69 \\
70-74 \\
75-79 \\
80-84 \\
85-89 \\
\text { over } 90\end{array}$ & $\begin{array}{c}-\overline{139 / 75} \\
137 / 77 \\
154 / 80 \\
147 / 87 \\
-\end{array}$ & $\begin{array}{c}138 / 74 \\
150 / 71 \\
150 / 73 \\
155 / 68 \\
157 / 69 \\
161 / 67 \\
-\end{array}$ & $\begin{array}{l}137 / 76 \\
143 / 78 \\
148 / 80 \\
153 / 82 \\
148 / 78 \\
162 / 85 \\
129 / 59\end{array}$ & $\begin{array}{c}\overline{151 / 82} \\
160 / 86 \\
166 / 86 \\
175 / 84 \\
170 / 90 \\
142 / 81\end{array}$ & $\begin{array}{c}\overline{149 / 80} \\
157 / 83 \\
166 / 87 \\
158 / 84 \\
147 / 79\end{array}$ \\
\hline Number of cases & 189 & 165 & $?$ & 150 & 120 \\
\hline
\end{tabular}

All the above figures are lower than those of Saller but higher than those of Willius. They agree that a rise of pressure is customary after the age of sixty, reaching a peak somewhere between seventy-five and eighty-nine but falling 
thereafter. More than this cannot be deduced without a careful analysis of the clinical material from which the figures were taken. The present study was an attempt to carry the work of Thompson and Todd a stage further by classifying the cases observed and trying to find some relationship between blood pressure, arteriosclerosis, mental state, and physical condition.

\section{Conditions AND STANDARDS}

The investigations were carried out on Chelsea pensioners, all tough veterans of the old professional British army. Their ages ranged from 65 to 92 and they comprised all men admitted to the Infirmary of the Royal Hospital, Chelsea, during a period of six months. Each patient was classified by blood pressure figures, the state of the arteries, renal concentration power, mental state, and physical condition. The blood pressure was taken usually once a week, but more often if the condition of a patient was changing rapidly. The method used was that recommended by the American Heart Association and the Cardiac Society of Great Britain and Ireland.

Owing to the evacuation of the Infirmary into temporary quarters, due to enemy action, the normal sources of $\mathrm{X}$-ray and pathological investigations were not available, so that clinical methods only were used.

Variations in blood pressure.-Weekly variations of pressure were frequent within narrow limits. For instance, one patient kept between 190/90 and 210/110 throughout the whole period under review. Another stayed between 120/70 and 140/80, and a third between $140 / 80$ and 160/90. Systolic figures appeared to vary about $20-25 \mathrm{~mm}$. and diastolic figures $10-20 \mathrm{~mm}$., but while the patient remained in his usual state, they rarely changed more than this. No significant pressure difference was found between the right and left arm of any patient, including those who were hemiplegic.

Infections, especially those with diarrhœa or prolonged pyrexia, almost always caused a fall in blood pressure. This might be as much as $50 \mathrm{~mm}$. (systolic) with pneumonia, $25 \mathrm{~mm}$. with enteritis, and $20 \mathrm{~mm}$. with bronchitis. Any form of cardiac failure also lowered the blood pressure, which might fall from 180/90 to 90/60 in a week. The later stages of cancer were also associated with a drop in pressure. One patient, observed over two and a half years, went from $200 / 90$ to $115 / 65$ before death, while another fell from $190 / 90$ to $110 / 60$ in a few weeks. This was observed in seven cases.

\section{The Blood Pressure}

Three main groups were noted. The first was composed of those who remained above $160 \mathrm{~mm}$. systolic throughout the period of observation. This was classed as raised blood pressure, and included 42 per cent of the total. The second consisted of those with systolic figures below $160 \mathrm{~mm}$. but above $115 \mathrm{~mm}$. The third was made up of those with systolic pressures under $115 \mathrm{~mm}$. and included 5 per cent of the total. While these groups were arbitrary ones, nevertheless they corresponded with certain clinical classes.

High blood pressure.-Fifty of the patients had mean systolic pressures over $160 \mathrm{~mm}$. during the period of investigation. Ten more, originally in this group, 
dropped to lower levels with cancer, infections, or heart failure. (These cases either died or became invalids, instead of living a fairly normal life as they had done before.) Both ninety-two year olds were in this class.

TABLE III

Age ANd Blood Pressure

\begin{tabular}{|c|c|c|c|c|c|}
\hline \multicolumn{3}{|c|}{ Age } & Total number & Systolic over $160 \mathrm{~mm}$. & Diastolic over $100 \mathrm{~mm}$. \\
\hline $\begin{array}{l}\text { Under } 70 \\
70-74 \\
75-79 \\
\text { Over } 80\end{array}$ & $\begin{array}{l}\ldots \\
\cdots \\
\ldots\end{array}$ & $\begin{array}{l}\ldots \\
\ldots \\
\ldots \\
\ldots\end{array}$ & $\begin{array}{l}26 \\
33 \\
34 \\
27\end{array}$ & $\begin{array}{l}40 \% \\
36 \% \\
51 \% \\
42 \%\end{array}$ & $\begin{array}{r}8 \% \\
12 \% \\
18 \% \\
4 \%\end{array}$ \\
\hline
\end{tabular}

Thirty-three of the men were physically active and twelve more only slightly incapacitated. Mentally, eleven were of normal adult intelligence, twentyfive were of normal senile intellect, and fourteen had some mental impairment. Eighteen had very thickened palpable arteries, while only two had arteries that were relatively soft. Nineteen had a specific gravity of urine below 1015 , but only two had albuminuria.

This group with raised blood pressure included many of the fittest men in the Infirmary. Eighteen of them had local disabilities, such as old injuries or impaired vision, which made them unsuitable for Chelsea with the possibility of air raids. The rest were suffering from such conditions as bronchitis, enlarged prostate, or mild senile dementia, while four were hemiplegic. The higher ranges of blood pressure were unusual, only eight patients having systolic figures over $200 \mathrm{~mm}$. and only thirteen having diastolic pressures regularly over $100 \mathrm{~mm}$.

Low blood pressure.-Six patients had systolic figures regularly below $115 \mathrm{~mm}$. and five more had similar pressures for long periods. The only survivor of the first class was a case of colitis, the others all dying of cancer or cardiac failure. The temporary members of the group suffered from chronic bronchitis (2), pneumonia, septicæmia, or sciatica. In each case the systolic pressure rose to a level of $130-140 \mathrm{~mm}$. on recovery.

\section{Arteriosclerosis and Mental Condition}

Arteriosclerosis.-Each patient was classified according to the state of his arteries as slightly thickened $(+)$, moderately thickened $(++)$, or considerably thickened $(+++)$. No case had soft vessels. Both radial, brachial, and temporal arteries were taken into consideration before grading. In fifty patients, the findings were compared with the state of the retinal arteries. Some local variations were often found, as in the case of a man of 84 whose right radial was considerably thickened, but whose other accessible arteries were just palpable, and the retinal vessels little thickened. Another, suffering from senile diabetes, had slightly thickened palpable arteries with a markedly arteriosclerotic fundus.

The oldest man with only slight thickening of the arteries was 84 . Five of the group had normal adult intelligence, while seven had ordinary senile mentality. 
Only one showed mental impairment-the diabetic referred to above. Eleven were active enough to walk in the grounds of the Infirmary and to go up and down stairs without difficulty. Only two had hypertension, while three sometimes had pressures below $115 \mathrm{~mm}$. systolic. This seemed to suggest a connexion between soft arteries and good physical and mental condition.

TABLE III

Arteriosclerosis and Blood Pressure

\begin{tabular}{|c|c|c|c|c|c|c|}
\hline \multicolumn{3}{|c|}{$\begin{array}{l}\text { Arterial } \\
\text { thickening }\end{array}$} & $\begin{array}{c}\text { Toal } \\
\text { number }\end{array}$ & $\begin{array}{c}\text { Raised } \\
\text { blood pressure }\end{array}$ & $\begin{array}{l}\text { Lowered } \\
\text { blood pressure }\end{array}$ & $\begin{array}{l}\text { Mentally } \\
\text { impaired }\end{array}$ \\
\hline $\begin{array}{l}\text { Slight } \\
\text { Moderate } \\
\text { Marked }\end{array}$ & $\begin{array}{l}\cdots \\
\cdots \\
\cdots\end{array}$ & $\begin{array}{l}\cdots \\
\cdots \\
\cdots\end{array}$ & $\begin{array}{l}13 \\
80 \\
27\end{array}$ & $\begin{array}{l}16 \% \\
38 \% \\
66 \%\end{array}$ & $\begin{array}{r}24 \% \\
4 \% \\
20 \%\end{array}$ & $\begin{array}{l}8 \% \\
22 \% \\
32 \%\end{array}$ \\
\hline
\end{tabular}

Twenty-seven had extremely thickened arteries. Each member of the group where the pressure was not raised was in a feeble physical condition, unfit for much exertion. Five were also mentally impaired. Eighteen normally had a raised pressure, six of them being over 80 . Eight of them had intelligence below normal senile standards: none were above it.

Out of fifty cases whose ocular fundi were examined, some thirty showed arteries thickened and tortuous in the centre of the disc, narrowing peripherally. Many of these had some irregularity in the lumen of the vessels. Sixteen had arteries that were narrowed, but more or less straight, throughout their course, not showing any irregularities. Two seemed to be normal and two had vessels that were difficult to see clearly. The state of the vessels appeared to have no relation to the level of blood pressure or the general state of the arterial tree, thirteen of the first class and eleven of the second having a raised pressure.

Of those with marked arteriosclerosis, the patients with raised blood pressure were, on the whole, more active and alert than the rest. It seemed that, over the age of seventy-five, marked thickening of the arteries was not important prognostically, especially when the blood pressure was raised. Below seventy and with relatively low blood pressure, some mental and physical impairment was usual. The power of recovery from injuries and infections was certainly poorer than in those with raised blood pressure who were a few years older.

Mental condition.-The mental state of patients was assessed as normal adult, normal senile, or impaired. The first class is self-explanatory. The second included those who could behave rationally and carry on a sensible conversation, but whose perceptions were somewhat dull and whose mental processes were slower than those of younger persons. The third class was composed of those who were clearly abnormal or subnormal.

Fifteen patients had normal adult intelligence. All were physically active and three actually employed on light duties in the infirmary. The oldest member of this group was 75 years of age. Eleven had a raised blood pressure and ten showed moderate thickening of the arteries, while none had extreme thickening. None of these cases had urine with specific gravity below 1015 . 
TABLE IV

Mental Condition and Circulation

\begin{tabular}{|c|c|c|c|c|c|c|c|}
\hline \multicolumn{3}{|c|}{$\begin{array}{l}\text { Mental } \\
\text { standard }\end{array}$} & \multirow{2}{*}{$\begin{array}{c}\begin{array}{c}\text { Total } \\
\text { number }\end{array} \\
15 \\
78 \\
27\end{array}$} & \multirow{2}{*}{$\begin{array}{c}\text { With raised } \\
\text { blood pressure } \\
73 \% \\
33 \% \\
50 \%\end{array}$} & \multicolumn{3}{|c|}{$\begin{array}{l}\text { Arterial thickening } \\
++++++\end{array}$} \\
\hline $\begin{array}{l}\text { Adult } \\
\text { Senile } \\
\text { Impaired }\end{array}$ & $\begin{array}{l}\ldots \\
\cdots \\
.\end{array}$ & $\begin{array}{l}. \\
\ldots \\
\ldots\end{array}$ & & & $\begin{array}{l}33 \% \\
10 \% \\
4 \%\end{array}$ & $\begin{array}{l}67 \% \\
66 \% \\
66 \%\end{array}$ & $\begin{array}{l}\overline{24 \%} \% \\
30 \%\end{array}$ \\
\hline
\end{tabular}

The normal senile group included seventy-eight patients, of whom twentyfive had raised blood pressure. Nineteen had marked arteriosclerosis, but in seven the thickening was only slight. Sometimes a man in this class would go downhill and become mentally impaired, and this was usually associated with some intercurrent disease or change in blood pressure. For example, a patient whose general levels were between 120 and $150 \mathrm{~mm}$. systolic became mentally worse on falling to $110 \mathrm{~mm}$.; this was a mild case of the syndrome of progressive cerebral ischæmia (Howell, 1941).

Twenty-seven cases were mentally impaired. Fourteen of these had a raised blood pressure and two had pressures below $115 \mathrm{~mm}$. systolic. Only one had slight thickening of his arteries and he had also an arteriosclerotic fundus oculi. Eighteen had moderate, and eight marked thickening of the arteries. Ten of the cases had a low specific gravity of urine, while only one had a figure above 1025. Six of these mentally impaired patients were hemiplegic. Thirteen were among the group whose fundus oculi was examined; nine had arteries thickened in the centre of the disc but narrowing peripherally, and the rest had vessels that were straight and narrow throughout their course.

\section{Discussion}

As we have seen above, a systolic pressure above $160 \mathrm{~mm}$. is common in old age. In the five-year age groups examined, the proportion varied from a third to a half of all cases. Among the oldest patients, the fittest were those with a high pressure; and a figure below $125 \mathrm{~mm}$. was only seen in three men over 80, two of whom were dying and the third of whom had exceptionally soft arteries for his age. The findings suggest that increased pressure is needed to offset the arteriosclerosis that becomes more pronounced with age (see Table V). Marked thickening of arteries with a relatively low blood pressure is associated with poor physical condition, while raised blood pressure and very thick arteries are compatible with relative fitness and activity. The connexion is not so clear in the case of mental impairment, but we can say that no man with very thickened arteries had adult intelligence and that no patient with impaired intellect had less than moderate arteriosclerosis.

Measurement of the specific gravity did not give much help in the assessment of a patient's condition, only 10 per cent of cases having a figure above 1025 for early morning urine. Robinson and Brucer (1939) suggest that old age depends on low weight, low blood pressure, and a slow pulse. Experience at the Royal Hospital, Chelsea, does not accord with this, however. Seven out of 
TABLE V

Age, Arteriosclerosis, and Raised Blood Pressure

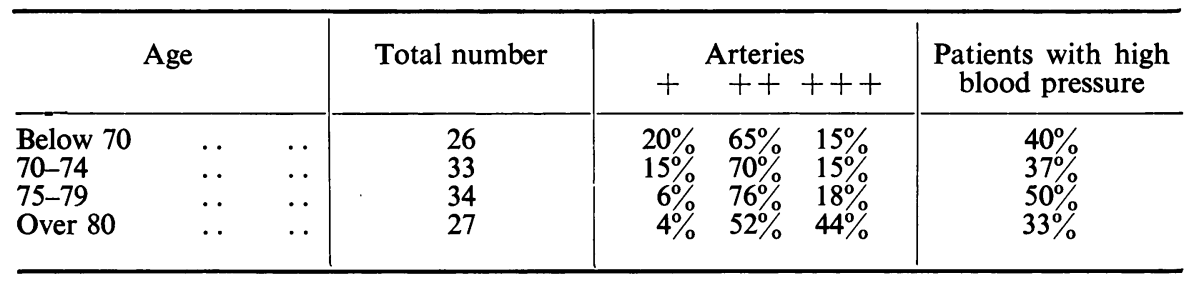

ten pensioners over ninety in recent years have been stout rather than thin: both ninety-two year olds in the present series had a systolic pressure habitually over $160 \mathrm{~mm}$., while a pensioner, killed by enemy action at the age of a hundred, had a pressure of $150 / 80$ during the last two years of his life. This man was also far from thin.

It seems that the raised blood pressure arising in old age is beneficent compared with that of younger persons. In the present series of cases, many of the younger men who had been admitted to the Royal Hospital as In-pensioners with high blood pressure, were in poor condition compared with their elders. As arteriosclerosis increases, a greater head of pressure is necessary to prevent ischæmia of vital organs or tissues, so that senile hypertension may well be compensatory in character. In the absence of raised pressure, vital ischæmia takes place, resulting in impaired function, either mental or physical. With the old man with raised blood pressure, cardiac defeat or a vascular accident eventually terminates life, but he is often spared the lingering existence, dependent on others for everything, that falls to the lot of some aged folk.

\section{SUMMARY}

A rise of systolic blood pressure is common after the age of sixty.

In the present series of 120 Chelsea pensioners, 42 per cent had systolic figures regularly over $160 \mathrm{~mm}$.

Cancer, cardiac failure, and infections often cause a fall in blood pressure.

Marked arteriosclerosis, in the absence of raised blood pressure, is usually associated with poor physical condition.

It is suggested that the raised blood pressure of old age is a form of compensation tending to prevent ischæmia of vital structures.

I should like to express my thanks to the nursing staff of the Royal Hospital, Chelsea, for their assistance in my investigations.

\section{REFERENCES}

Bowes, L. M. (1917). J. Lab. clin. Med., 2, 256.

Howell, T. H. (1941). Postgrad. med. J., 17, 195.

Richter, A. (1925). Deutsch. Arch. klin. Med., 148, 111.

Robinson, S. C., and Brucer, M. (1939). Arch. intern. Med., 64, 409.

Thewlis, M. W. (1941). The Care of the Aged (Kimpton).

Thompson, R. J. C., and Todd, R. (1922). Lancet, 2, 503.

Willius, F. A. (1931). Amer. J. med. Sci., 182, 1. 